\title{
SEVERE VALGUS DEFORMITY OF THE KNEE: DESCRIPTION OF NEW SURGICAL TECHNIQUE FOR ITS CORRECTION
}

Robson Rocha da Silva', Marcos Almeida Matos ${ }^{2}$, Maurício Pimentel ${ }^{3}$, Bruno Jacomeli Martins ${ }^{4}$, Rafael Valadares Oliveira ${ }^{4}$

\section{ABSTRACT}

Varus supracondylar osteotomy of the femur is the established procedure for treating painful knees that present lateral arthrosis and valgus deformity. In descriptions of the conventional surgical techniques, there are divergences regarding the location, access route, correction level, fixation type and area for synthesis insertion. This is most evident in cases of severe valgus with angles greater than $30^{\circ}$ and distal femoral deformation, in association with hypoplasia of the lateral condyle. The authors describe a new surgical technique for distal femoral osteotomy, based on anatomical and geometrical criteria, which was developed in their clinic for treating severe valgus cases, and they present one of the cases treated. In the new technique, the wedge to be surgically resected has an oblique direction and the format of an isosceles triangle. This new proposal thus seeks to resolve problems that have been presented in such cases, through enabling valgus correction without causing any new deformity of the distal femur. Good cortical bone contact is promoted, and application of a stable synthesis system is made easier. However, the age limits for such patients and the degree of knee arthrosis that might contraindicate this procedure remain unknown. Hence, a larger sample and longer follow-up for operated cases are required.

Keywords - Osteotomy; Femur; Knee; Osteoarthritis

\section{INTRODUCTION}

Varus rotational supracondylar osteotomy of the femur is the established procedure for treating knees with valgus deformity associated with pain and/or lateral arthrosis ${ }^{(1)}$. Jackson et $\mathrm{al}^{(2)}$ presented the first description of osteotomy to correct a valgus knee. In 1973 , Coventry ${ }^{(3)}$ established that only distal osteotomy of the femur would be capable of transferring the load to the medial compartment in cases of angular valgus deformities greater than $12^{\circ}$, associated with obliquity of the joint line greater than $10^{\circ}$.

In 1984, Insall ${ }^{(4)}$ made reference to the scarcity of studies on this type of treatment. In 1992, Navarro and Laredo $^{(5)}$ showed that the literature on this topic diverged with regard to the site, access route, degree of correction, type of fixation and region for placement of the synthesis. These findings have given rise to a series of uncertainties regarding this subject.
Recent studies have not clearly addressed the treatment of severe cases of valgus knee, such as those with angles greater than $30^{\circ}$ and distal femoral deformation associated with hypoplasia of the lateral condyle. These cases are difficult to treat using the methods presented in the literature, because of lack of capacity to correct, or because of the disparity of width of the distal and proximal segments after resection of the wedge, or because of lack of cortical bone contact, thus allowing loss of correction or hypercorrection in varus ${ }^{(6)}$.

The aim of this study was to describe a new surgical technique for distal femoral osteotomy, based on anatomical and geometrical criteria, which was developed at our service for severe cases of valgus knee.

\section{DESCRIPTION OF THE TECHNIQUE}

This study consists of an experimental presentation of a new surgical technique performed on a single

1 - Orthopedist and Head of the Knee Group, Hospital Santa Izabel, Santa Casa de Misericórdia da Bahia, Salvador, BA, Brazil.

2 - Adjunct Professor; PhD from the Bahia School of Medicine and Public Health, Salvador, BA, Brazil.

3 - Resident Physician at Hospital Santa Izabel, Santa Casa de Misericórdia da Bahia, Salvador, BA, Brazil.

4 - Orthopedist at Hospital Santa Izabel, Santa Casa de Misericórdia da Bahia, Salvador, BA, Brazil.

Work performed in the Knee Group, Hospital Santa Izabel, Santa Casa de Misericórdia da Bahia, Salvador, BA.

Correspondence: Av. Orlando Gomes, Condomínio Veredas Piatã, Quadra B, Lote 07, Piatã, 41650-010 Salvador, BA - E-mail: robroc@superig.com.br

Work received for publication: June 2, 2011; accepted for publication: August 4, 2011

The authors declare that there was no conflict of interest in conducting this work 
anatomical model that was based on a real case. The pre and postoperative radiographic data on a patient operated at our service were accessed with the aim of building up an anatomical model based on a real case. The preoperative radiographs and tomographic scans were sent to a laboratory, where a polyurethane model of the distal femur was constructed so as to reproduce the deformity encountered in this patient.

All of the preoperative planning was done using AP and lateral radiographs on the patient. The planning consisted of marking out the wedge to be surgically resected. A polyurethane model was used to make a step-by-step presentation that simulated the surgical procedure.

Both the preoperative planning and the surgical technique were photographed using a digital camera in order to provide comprehensive detailed illustrations of the procedure.

\section{SURGICAL TECHNIQUE}

The theoretical basis of our technique was the geometrical principles described below ${ }^{(7)}$ :

1) The sum of all the angles of a triangle is always $180^{\circ}$.

2) An isosceles triangle is composed of at least two sides of the same length and two equal (congruent) angles. The angle formed by the sides of the same length is called the vertex angle and the other two are called the base angles (Figure 1).

3) "If a triangle has two sides of the same length, then the angles opposite these sides are congruent". In other words, in an isosceles triangle, the base angles are equal (isosceles triangle theorem) (Figure 1).

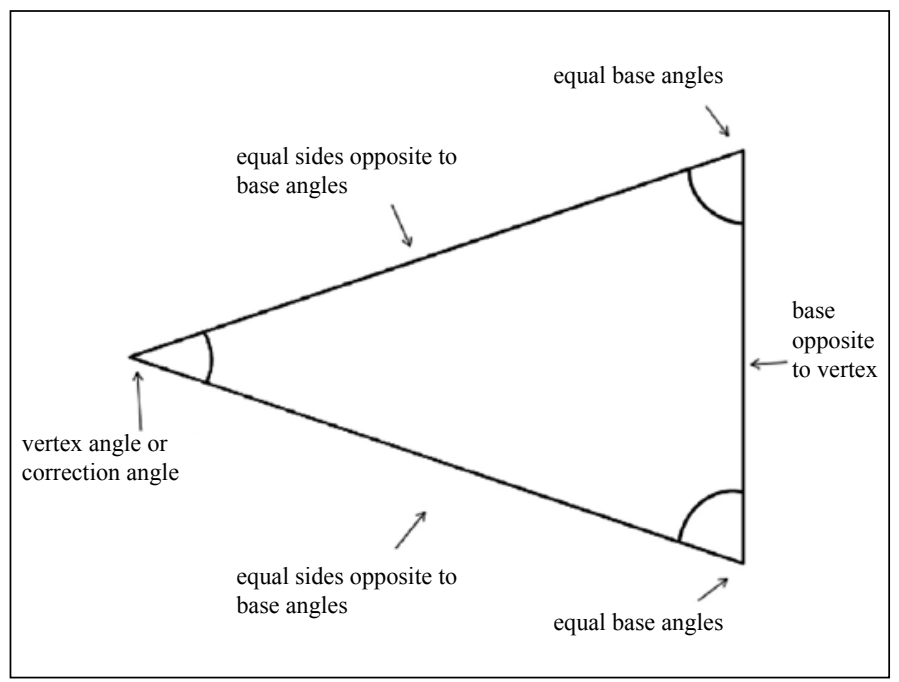

Figure 1 - Isosceles triangle.

Rev Bras Ortop. 2012;47(2):251-56
The main modifying element of the new technique consists of resection of a wedge that will have the format of an isosceles triangle. The vertex angle is the deformity correction angle, located within the lateral cortical bone of the femur. The base of the wedge, opposite the vertex, is located in the medial cortical bone (Figure 2).

The geometrical foundations described above help in obtaining the measurements of the wedge and determining its location in the femur. Thus, if the magnitude of the vertex angle is known, the other two angles can be obtained, from the following formula:

$$
\mathrm{a}^{\mathrm{o}}=\frac{180-\text { correction angle }}{2}
$$

$\mathrm{a}^{\mathrm{o}}=$ base angles (always equal in an isosceles triangle)

For example, if the correction angle is $30^{\circ}$ :

$\mathrm{a}^{\mathrm{o}}=\frac{180^{\circ}-30^{\circ}}{2} \quad \mathrm{a}^{\mathrm{o}}=\frac{150^{\circ}}{2} \quad \mathrm{a}^{\mathrm{o}}=75^{\circ}$

In this manner, by locating the lower point of the base on the femur and knowing what the base and vertex angles are, it is possible to trace out the exact location of the triangle on the radiograph, with the aid of a goniometer.

These are the geometrical and anatomical principles of the new technique, which is presented in two phases: preoperative planning and operative phase.

\section{Preoperative planning}

In the preoperative phase, the first step is to define the valgus angle that is to be corrected, through measurement of the anatomical axis. The objective of the surgery is to take the anatomical axis to $0^{\circ}$, thus transferring the load to the medial compartment, as recommended in other studies ${ }^{(1,3)}$.

The exact location of the osteotomy is established on the AP radiograph of the knee, by tracing
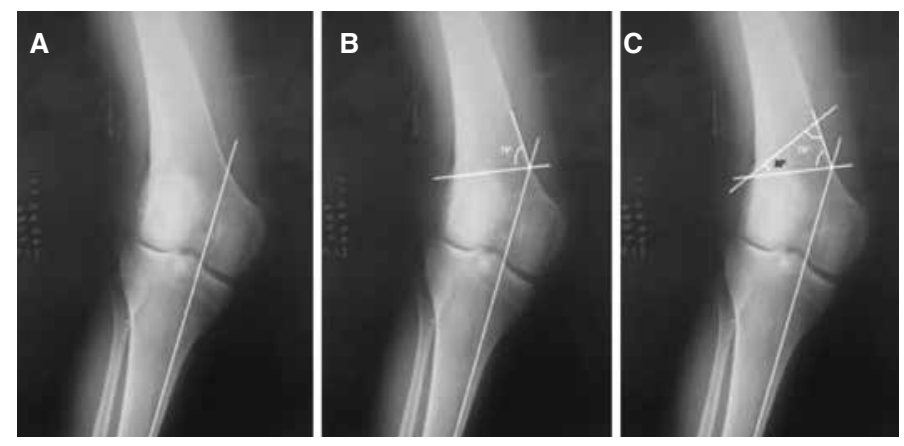

Figure 2 - (A) Lower point, at base of triangle. (B) Point at vertex, in lateral cortical bone. (C) Isosceles triangle. 
out a line over the medial cortical bone of the tibial diaphysis and its prolongation as far as the medial cortical bone of the femur, on which the lower point of the base of the triangle to be defined is marked out (Figure 2A). Following this, taking the medial cortical bone of the femur to be the base of the isosceles triangle, the base angle (which in the example above was $75^{\circ}$ ) and the line equivalent to the lower side of the triangle are traced out. The prolongation of this line will define the vertex of the oblique wedge in the lateral cortical bone (Figure 2B). Next, the vertex angle and upper side are traced out, thus completing the formation of the isosceles triangle, as established by the technique (Figure 2C).

After defining the correction angle and its position on the radiograph, the osteotomy is planned using the technique of overlapping traces ${ }^{(8)}$ (Figure $3 \mathrm{~A}$ and B). Planning for the fixation is done using transparent templates with the outlines of the implants to be used. We recommend using a cortical traction screw, together with a long $95^{\circ}$ fixed-angle plate system, applied laterally.

The correction attained and the entire strategy for stable fixation of the procedure is checked in advance. A mold of the resection wedge is also produced, to be sterilized and applied as a guide during the surgical procedure.

\section{Operative phase}

On a radiotransparent table, the patient is anesthetized in dorsal decubitus, by means of a subvastus access. The anterior and lateral cortical bone of the distal femur is identified, and the lower point of the opening angle of the resection wedge is marked out on this. Using an electric scalpel, the correction angle is traced out

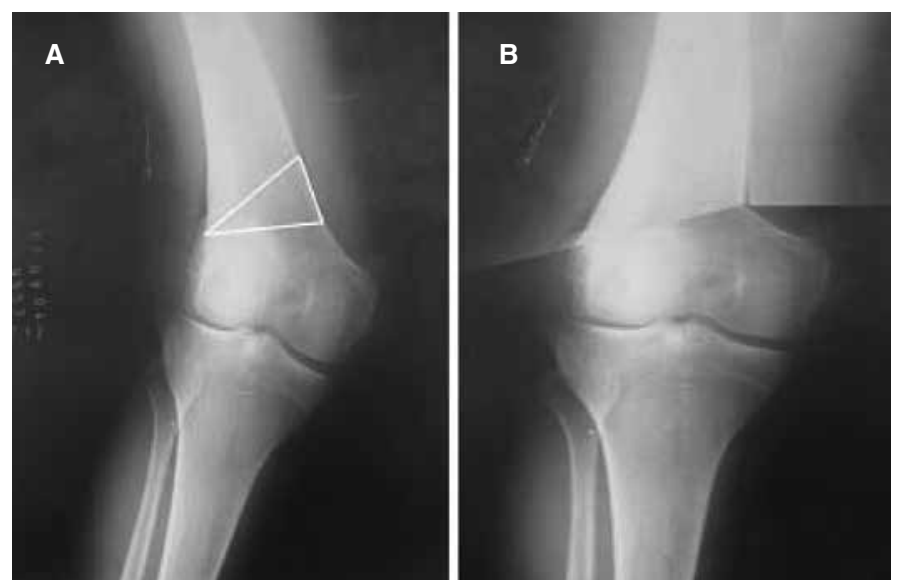

Figure 3 - (A) Definition of resection wedge. (B) Projection of correction on AP radiograph. using the guide wedge (graduated in millimeters), in accordance with the planning. This needs to be present in the surgical theater (Figure 4).

We recommend that the angle marked out should be two degrees less than stated in the planning, in order to avoid overcorrection, given that the radiograph increases the dimensions of the real image by up to 15 to $20 \%$. If this results in undercorrection, it will be possible to increase the angle of the resection wedge and correct the deformity (Figure 5).

The osteotomy of the resection wedge is performed using a nitrogen saw. Subsequently, after wedge closure, an oblique trace is produced on the distal femur, as planned previously (Figures 6 and 7).

A cortical traction screw is used to compress the focus of the osteotomy, and this is stabilized using a long $95^{\circ}$ fixed-angle plate on the lateral cortical bone of the distal femur. Because of the metadiaphyseal position of the osteotomy, a bone graft can be placed to stimulate consolidation (Figures 8 and 9).

After placement of a suction drain, the operative wound is closed in layers. During the postoperative period, the patient is kept with the knee in a flexed position. Assisted active and passive movements are made, up to the pain threshold. Early walking using two crutches, with loading on the operated limb, is encouraged. Load-bearing will be allowed on around the $45^{\text {th }}$ day, after radiological consolidation has been achieved.

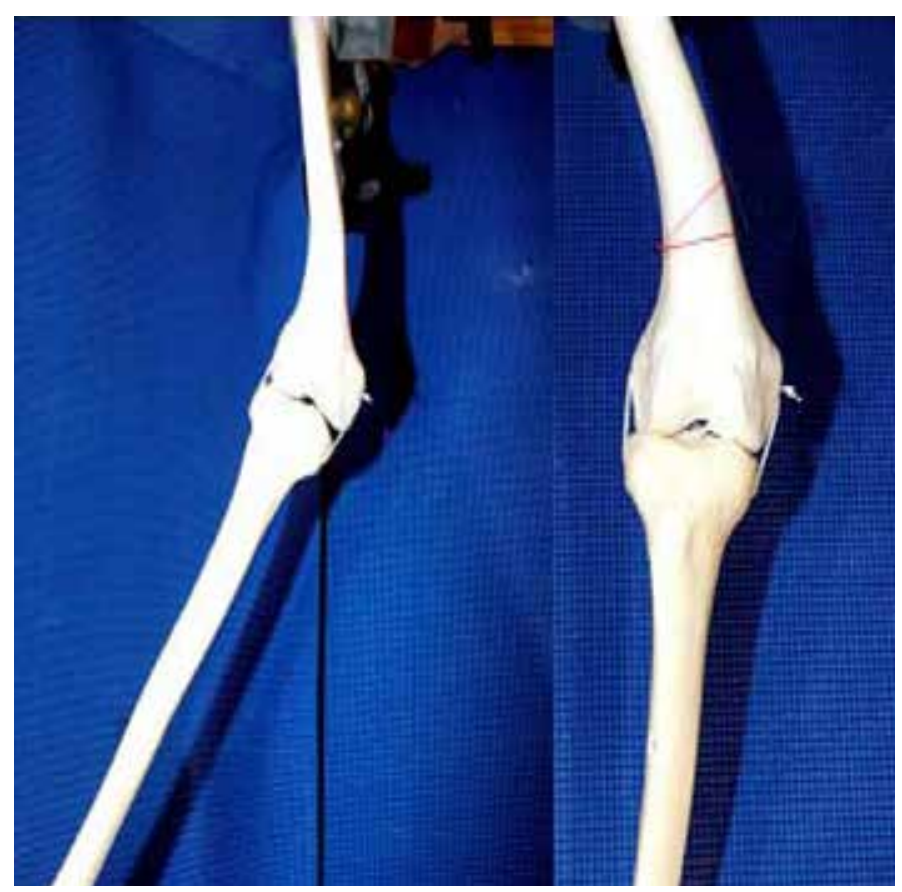

Figure 4 - Anatomical model with mold of resection wedge. 


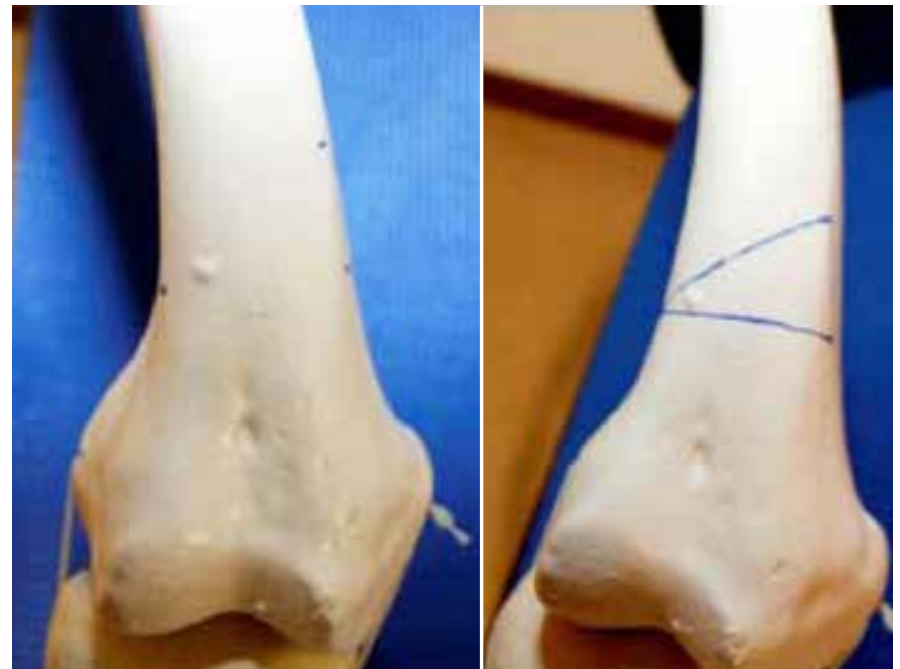

Figure 5 - Marking for resection wedge, from guide constructed during surgical planning.

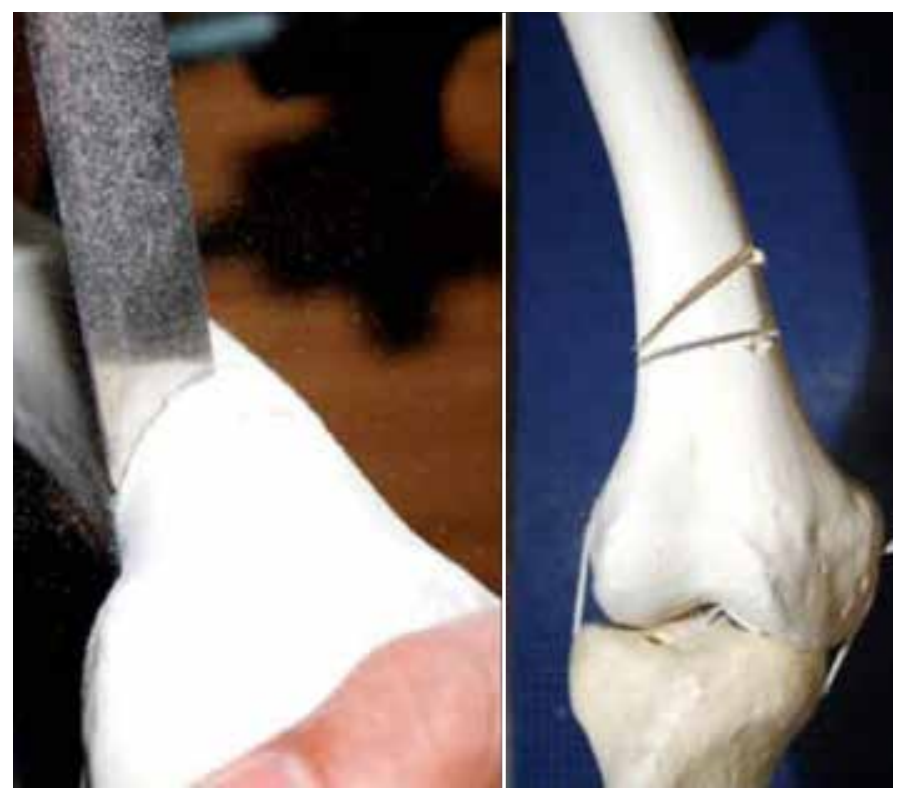

Figure 6 - Femoral osteotomy using nitrogen saw.

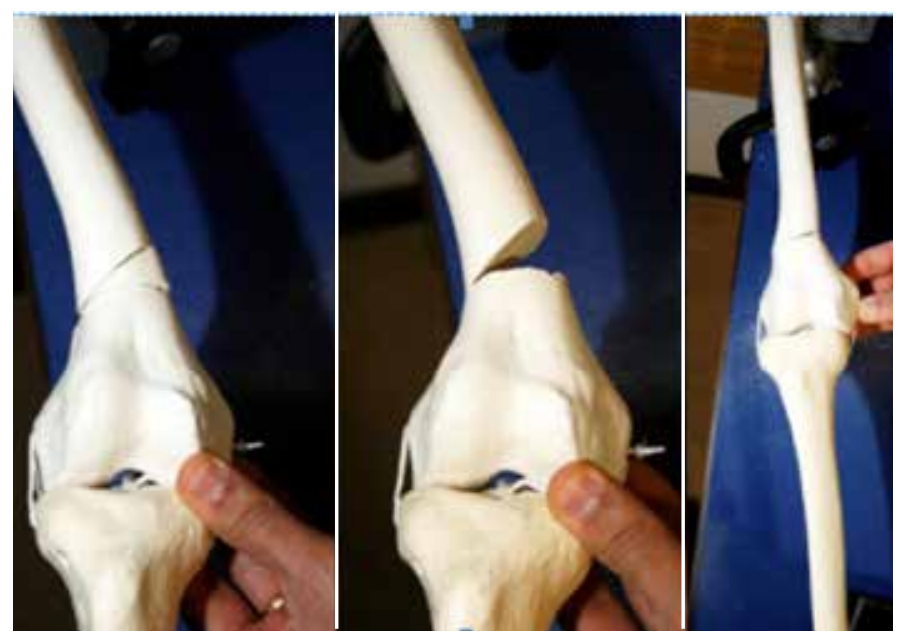

Figure 7 - After closure of the wedge, an oblique trace is produced on the distal femur.

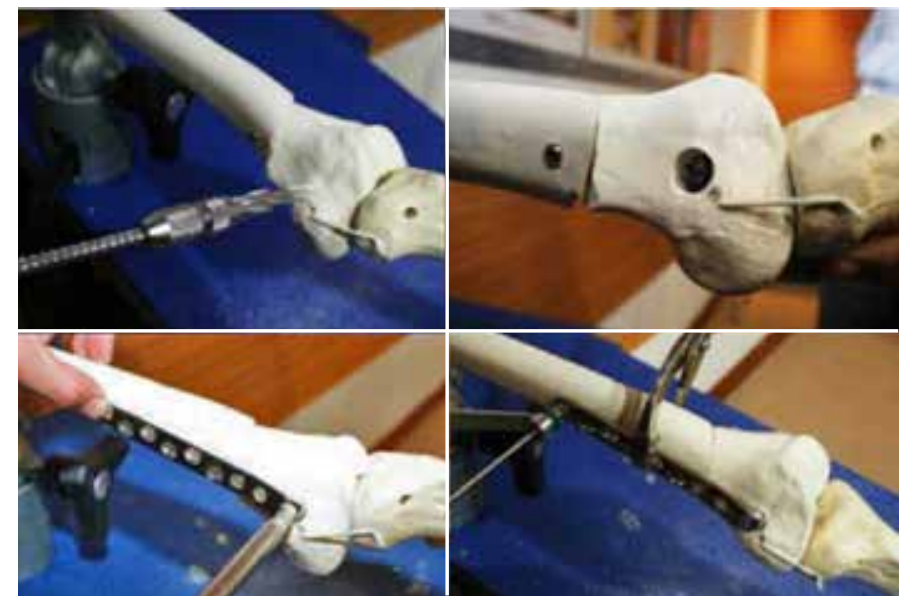

Figure 8 - Stabilization of the osteotomy using synthesis material described above.

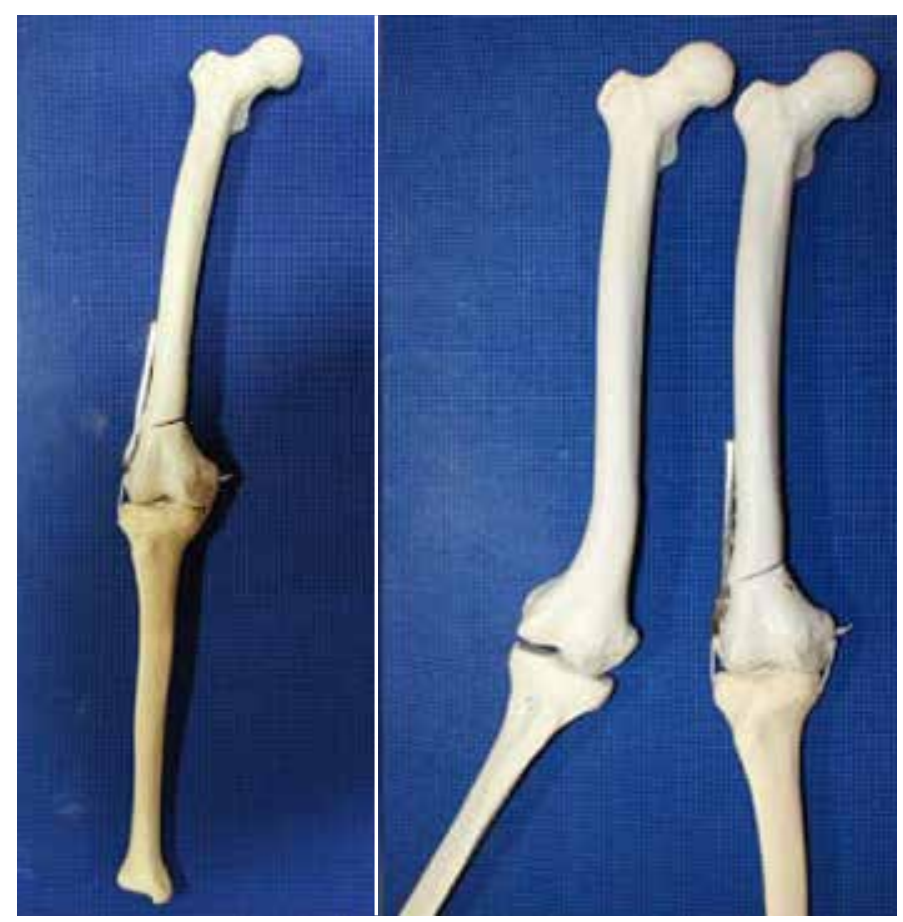

Figure 9 - Surgical result from correction in anatomical model.

\section{DISCUSSION}

Valgus deformity of the knee, due either to trauma or to development, is much less common than varus deformity ${ }^{(9)}$. Although varus rotation osteotomy of the distal femur to treat this abnormality is technically well established and constitutes an option for the majority of surgeons, it has not presented absolutely convincing results in long-term asessments ${ }^{(6,9)}$.

Very severe valgus, of more than $30^{\circ}$, generally results from bone dysplasia or growth disorders of the lateral epiphyseal plate, and is associated with other deformities of much greater complexity. The progressive nature of this deformity leads to 
contracture of the lateral structures, especially the iliotibial band. When the causal element occurs during childhood, at the end of disproportional growth there will be a severe deformity, with alteration of the original anatomy due to hypoplasia of the lateral femoral condyle. The earlier the problem occurs, the greater the deformity will be.

Subtraction osteotomy carried out in the traditional region, i.e. the metaphyseal region, gives rise to incongruence in the cortical support between the proximal and distal extremities ${ }^{(5)}$ (Figure $10 \mathrm{~A}$ and B). In these cases, the wedge to be resected usually resembles a scalene triangle, i.e. in which all three sides are different. Hence, after resection of the wedge, closure of this angle will not allow the cortical bone on each side to be in contact, because of the significant difference in thickness between the proximal and distal fragments.

Navarro and Laredo reported that this difference could cause undesirable interpenetration of the fragments and even support of the proximal fragment on the synthesis material ${ }^{(5)}$. Excessive impaction also acts as a factor determining overcorrection in varus over the long term, which may occur in up to $31.25 \%$ of the patients, as observed by Severino et $\mathrm{al}^{(9)}$.

Moreover, after concluding osteotomy, the axis of the epiphysis is shifted medially in relation to the axis of the diaphysis, which may add complications in the event of any future total arthroplasty ${ }^{(10)}$.

The solution proposed here for such cases therefore seeks to resolve the problems presented, by producing valgus correction without causing new deformity of the distal femur. Through resection of a bone wedge of equal sides, the medial column is shortened, thus reducing the tension on the fascia lata. Good cortical bone contact is also promoted, thereby avoiding interpenetration and secondary deformity of the distal femur, in varus. This facilitates application of a stable synthesis system (Figure $11 \mathrm{~A}$ and B).

Osteotomy performed outside of the traditional site, with greater obliquity of the angle and at a more proximal location, promoted the desired effect, i.e. resection of a wedge in the shape of an isosceles triangle, thereby making it possible to restore the alignment with cortical support after closure of the wedge.

In 2001, Surer ${ }^{(10)}$ presented the advantages of oblique osteotomy for correction of valgus knee. According to this author, oblique osteotomy promotes maximum

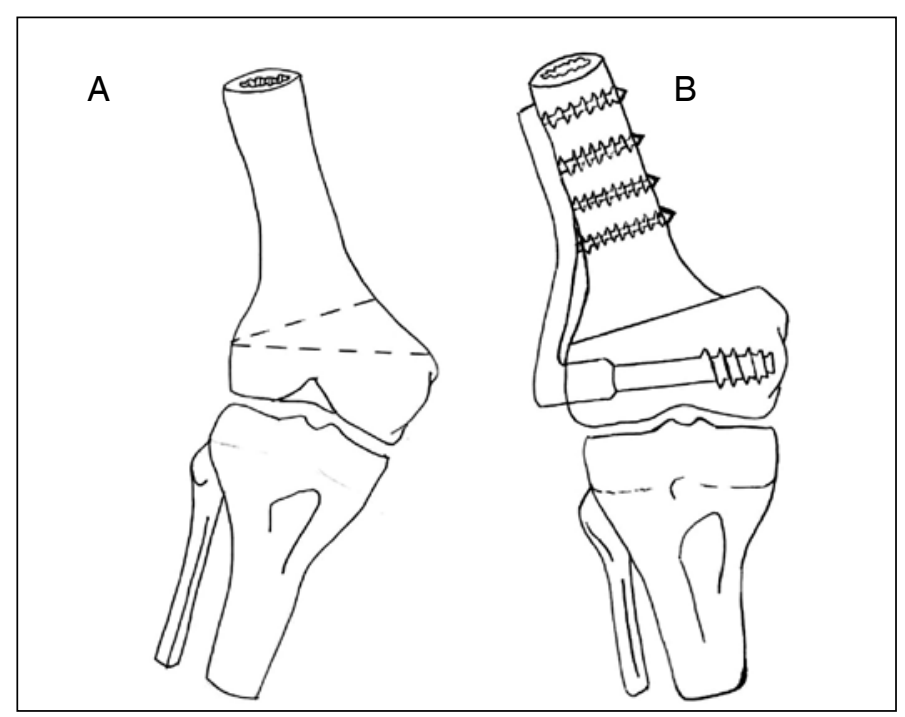

Figure $10-(A)$ Schematic drawing of the traditional site for varus rotational osteotomy. (B) Schematic drawing demonstrating the incongruence of the cortical support after closure of the resection wedge.

A

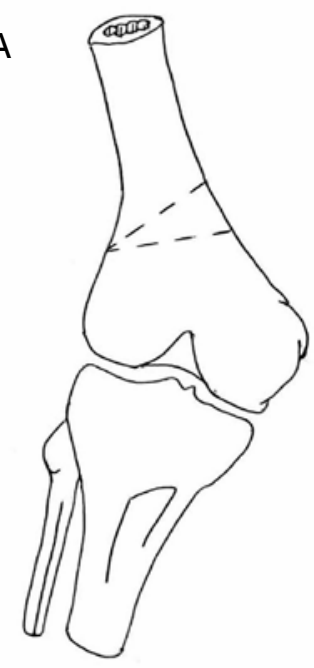

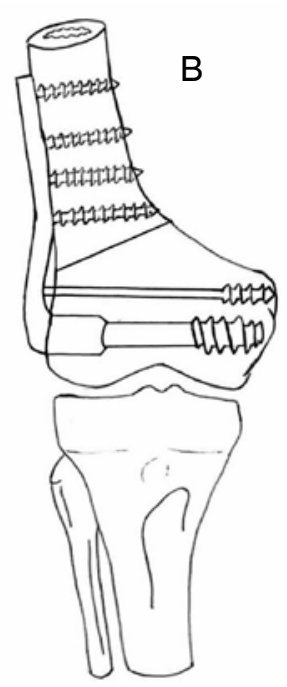

Figure 11 - (A) Schematic drawing of the most proximal site of the osteotomy. (B) Schematic drawing demonstrating the cortical alignment after closure of the wedge.

bone contact, with stable cortical pressure between the segments. This was observed in a series of 22 patients in which consolidation was achieved without abnormalities of distal femoral shape. This author concluded that the technique avoided the problems of the traditional technique and that the greater contact area facilitated bone consolidation, thereby simplifying the application of the fixation material. However, Surer ${ }^{(10)}$ did not make any reference to valgus cases of greater severity, since the maximum valgus in his sample was $22^{\circ}$, and he did not present the surgical technique in a detailed manner. 
Despite the more proximal location of the osteotomy, we have not observed any difficulties regarding consolidation in our cases. Our patients were younger (under the age of 25 years) and stable fixation of the osteotomy was achieved using a long plate with the principle of interfragmentary compression, so as to support reduction during the consolidation $\operatorname{process}^{(9)}$.

Prior analysis on the valgus to be corrected is essential. This is done by means of evaluation of the mechanical axis and correction angle obtained from AP radiographs, along with surgical planning using templates, as referred to in the literature ${ }^{(9)}$.

One likely complication from this type of osteotomy is the bone consolidation, given that the procedure is performed on the metaphyseal-diaphyseal portion of the femur, which is a region with less area of spongy bone. However, this problem can be minimized through using more appropriate implants and using bone grafts, or by restricting the procedure to younger patients in whom bone consolidation occurs more efficiently.

\section{CONCLUSION}

The new technique for varus rotation osteotomy, with a wedge of equal sides, shows promise for correcting severe cases of valgus in which there is concomitant hypoplasia of the lateral femoral condyle and retraction of the iliotibial band.

The surgical technique presented is therefore indicated for young patients with severe valgus deformity who present the initial stages of arthrosis, restricted to the lateral compartment of the knee. In these cases, surgery in the metaphysis-diaphysis region of the femur would be justified as a surgical alternative for halting the deleterious effect of overloading on the lateral compartment, even with greater risk of complications during consolidation.

However, we do not yet have any idea of the age limits or limits relating to the degree of arthrosis that might contraindicate this procedure. It will only be possible to make these definitions through clinical studies on samples of appropriate size and length of follow-up.

\section{REFERENCES}

1. Oliveira LP, Elias N, Cunha S, Mesquita KC. Osteotomia varizante distal do fêmur no tratamento do joelho valgo associado à artrose unicompartimental. Rev Bras Ortop. 1993;28(1/2):85-8.

2. Jackson JP, McDermott AG, Finkelstein JA, Farine I, Boyton EL, Maclntosh, $\mathrm{DL}$, et al. Osteotomy for osteoarthritis of the knee. J Bone Joint Surg Br. 1958;40:826.

3. Coventry MB. Osteotomy about the knee for degenerative and rheumatoid arthritis. J Bone Joint Surg Am. 1973;55(1):23-48.

4. Insall JN. Osteotomy. In: Surgery of the knee. New York: Churchill Livingstone; 1984. p. 551-85.

5. Navarro RD, Laredo JF. Correção da deformidade em valgo do joelho, por via de acesso anterior, pela osteotomia de subtração supracondiliana do fêmur. Rev Bras Ortop. 1992;27(4): 217-21,

6. Navarro RD, Queiroz AAB, Carneiro Filho M, Cortelazo MJ, Affonso Filho AA. As complicações nas osteotomias valgizantes e varizantes do joelho. Rev Bras Ortop. 1997;32(5):358-62,

7. Dolce O, Pompeo JN. Fundamentos de matemática elementar. São Paulo: Atual; 1995.

8. Muller ME, Allgower M, Schneider R, Willenegger H. Manual de Osteossíntese: técnicas recomendadas pelo grupo AO-ASSIF. 3a. ed. São Paulo: Manole; 1993.

9. Severino NR, Camargo OPA, Aihara T, Cury RPL, Oliveira VM, Barbi L, et al. Osteotomia supracondiliana femoral no tratamento da deformidade em valgo do joelho. Rev Bras Ortop. 1998;33(4):282-6.

10. Surer P. Advantages of oblique femoral osteotomy for varisation of the lower part of the femur: twenty-two cases. J Bone Joint Surg Br. 2001;83(Suppl 1):67-8. 